\title{
Tanda Pagar (\#) Sebagai Identitas Pesan Pada Komunitas Virtual
}

\author{
Urip Mulyadi dan Lisa Fitriana \\ (oeripmulia@unissula.ac.id, lisafitriana.lf@gmail.com) \\ (Program Studi Ilmu Komunikasi, Unissula; Magister Ilmu Komunikasi, FISIP, \\ Undip)
}

\begin{abstract}
Computer Mediated Communication or CMC is able to present a virtual community. where the people inside have the same interest to share information related to events, activities, competitions, entertainment, history, event and others in Semarang City for publication. This research attempted to describe that hashtags can be utilized as the identity of a message in a communications network on Facebook Group MIK Semar. The results of this study are hashtags have changed how we build a virtual community, as the use of hashtags in facebook group MIK SEMAR as message identity to build better relationship and support communication among its members.
\end{abstract}

Keywords: Virtual Community, Social Media, Hashtags

\begin{abstract}
Abstrak
Computer Mediated Communication atau CMC mampu menghadirkan komunitas virtual. Grup Facebook MIK Semar juga merupakan bagian komunitas virtual dimana orang-orang yang ada di dalamnya memiliki kepentingan yang sama untuk saling berbagi informasi terkait dengan peristiwa, kegiatan, lomba, hiburan, sejarah, event dan lain-lain di Kota Semarang untuk dipublikasi umum. Penelitian ini bertujuan untuk menggambarkan bahwa hashtag atau tanda pagar (\#) mampu dimanfaatkan sebagai identitas pesan dalam jaringan komunikasi pada Grup Facebook MIK Semar. Hasil Penelitian ini adalah hashtags telah merubah bagaimana kita membangun sebuah komunitas virtual, sebagaimana penggunaan hashtags dalam komunitas virtual Grup Facebook MIK SEMAR sebagai identitas pesan untuk membangun hubungan yang lebih baik dan mendukung komunikasi diantara anggotanya.
\end{abstract}

Kata Kunci: Komunitas Virtual, Media Sosial, Hashtags 


\section{Pendahuluan}

Perkembangan teknologi
telah mampu menarik berbagai
kalangan masyarakat membentuk
komunitas baru di dunia
maya.Kehadiran media sosial yang
digunakan sebagai sumber informasi
masyarakat tersebut telah mengubah
pola interaksi sosial atau interaksi
antarindividual.Media sosial juga
memberikan ruang kebebasan bagi
semua pengguna media yang dinilai
sebagai bagian dari kehidupannya.
Menurut Kaplan dan Haenlin (2010:
59) media sosial merupakan saluran
yang dapat digunakan dengan mudah
untuk berpartisipasi, berbagi dan
menciptakan isi meliputi blog,
jejaring sosial, wiki, forum di dunia
virtual. Media sosial sebagai "sebuah
kelompok aplikasi berbasis internet
yang membangun atas dasar ideologi
dan teknologi web 2.0, dan yang
memungkinkan
content" .

Flew ( dalam Watie, 2012) menjelaskan bahwa new media merupakan media yang menawarkan digitisation, convergence, interactiviy, dan development of network terkait pembuatan pesan dan penyampaian pesannya.

Layaknya forum diskusi, sebuah web forum dapat juga menampung ide, pendapat dan segala informasi dari para anggotanya sehingga dapat saling berkomunikasi atau bertukar pikiran antara satu sama lainnya. Sebuah forum online biasanya memiliki suatu pokok bahasan tertentu, namun tidak menutup kemungkinan meluas ke berbagai pokok bahasan.Pada dasarnya, forum online merupakan sebuah papan pengumuman yang tersedia dalam bentuk online. Namun saat ini sebuah forum online mengalami perluasan fungsi, yaitu tidak hanya sekedar berbagi informasi melainkan sebagai sarana akomodasi antarsesama pengguna dan pihak yang memiliki forum 
tersebut (Hermawan, 2009:12).Salah satu media sosial yang sering digunakan untuk membentuk komunitas online adalah Facebook. Penggunaan Facebook dapat memudahkan seseorang dalam menemukan teman baru atau teman lama, informasi topik-topik terbaru, hingga berkumpul dalam komunitas online dalam upaya membangun opini.

Menurut laporan riset We Are Social dan Hootsuite (2017) yang dilansir pada bulan April lalu menunjukkan bahwa Facebook kian mendominasi jagat media sosial dengan jumlah 1.968 miliar pengguna aktif. Peringkat pertama diduduki oleh Amerika Serikat dengan 219 juta pengguna atau $11 \%$, kedua adalah India dengan 213 Juta pengguna atau $11 \%$, disusul Brazil dengan 123 juta pengguna atau $6 \%$ dan Indonesia menduduki peringkat4 dengan 123 juta pengguna atau 6 $\%$. Selain itu menurut Survey yang dilakukan oleh Asosiasi

Penyelenggara Jasa Internet Indonesia(APJII) bulan Oktober tahun $2016 \quad$ (APJII,2016) menunjukkan pengguna internet Indonesia adalah 132,7 juta dari total populasi penduduk Indonesia 256,2 juta orang. Jika kita lihat pengguna dari kedua survey diatas menunjukkan bahwa pengguna facebook di Indonesia lebih dari $90 \%$ dari pengguna internet dimana $65 \%$ pengguna internet berada di Pulau Jawa.

Internet merupakan satu-
satunya yang terpenting yang
dibangun dalam bidang komunikasi
kontemporer seperti saat ini, yang
mana diproduksi secara global
"ruang publik" dimana dalam
teorinya setiap individu dapat
mengakses atau terlibat langsung
dalam forum global dimana mereka
diperbolehkan untuk
mengekspresikan argumennya tanpa
mediasi, seleksi atau sensor.
Bagaimanapun yang harus
dipertanyakan adalah seberapa masif


dari obrolan apa yang terjadi dalam forum online seperti youtube, myspace, facebook dan blogs, chatrooms akan memenuhi kriteria kondisi ruang publik sebagai forum untuk mengkritik dan debat rasional. Yang terpenting adalah kita memahami dulu arena ideologi Jurgen Habermas dalam konsep "ruang publik". Habermas mendefinisikan ruang publik sebagai "ranah dimana kehidupan sosial kita dalam suatu hal yang dipandang sebagai opini publik dapat terbentuk" (Habermas dalam Ubayasiri,2006:4).

Saat ini, di Indonesia banyak bermunculan komunitas virtual yang dibentuk berdasarkan wilayah baik dalam level kabupaten, Kota maupun Provinsi. Misalkan saja Grup Ungaran, Kabar Salatiga, Liputan Terkini Kendal, Media Informasi Kota Demak, Media Informasi Bojonegoro dan lain-lain. Dimana masing-masing komunitas virtual tersebut memiliki jumlah anggota yang bervariasi, rata-rata berjumlah puluhan ribu bahkan ratusan ribu.

Salah satu forum online yang ada adalah Grup Facebook Media Informasi Kota Semarang (MIK SEMAR). MIK SEMAR adalah sebuah rumah besar di dunia maya bagi warga kota Semarang untuk berbagi informasi diantara warga tentang peristiwa, kegiatan, lomba, hiburan, sejarah, event dan lain-lain di Kota Semarang untuk dipublikasikan umum.

Grup Facebook Media Informasi Kota Semarang (MIK Semar) merupakan grup yang dikenal sebagai penampung aspirasi, kritik, dan segala masalah terkait Kota Semarang yang disampaikan khalayak dunia maya (netizen), seperti dikutip dari halaman grup Facebook MIK SEMAR, hingga November 2017 ini member atau anggota dari Grup MIK Semar sudah mencapai 322.360 pengguna facebook, grup ini juga paling 
banyak member-nya diantara grup facebook lain tentang Kota Semarang dengan jumlah unggahan aktif mencapai 4530 unggahan. Grup Facebook lain diantaranya adalah Informasi Seputar Kota Semarang (ISKS) dengan 15.738 anggota (members), Media Informasi Publik Semarang (MIP Semar) dengan 7.935 anggota (members), dan Semarang $20.154 \quad$ anggota (members).

Grup Facebook ini memungkinkan setiap orang untuk dapat berbagi informasi pada khalayak lain yang tergabung dalam grup, dan setiap orang di dalam grup tersebut memiliki otoritas memilih dan membuat sendiri opini yang mereka inginkan. Di Grup MIK Semar masyarakat diberikan kebebasan untuk mengemukakan pendapatnya, namun harus bertanggungjawab terhadap unggahannya.Artinya unggahan tidak mengandung unsur SARA, pornografi dan tidak bertentangan dengan hukum di Indonesia, dalam hal ini adalah UU ITE.

\section{Dalam Grup MIK Semar} dikenal dengan adanya Dalang Utama, yakni admin yang memiliki kewenangan untuk mengendalikan dan menjadi pemimpin di grup dunia maya ini.Dibawahnya ada punggawa, yakni admin yang berhak untuk menyaring berbagai unggahan yang dinilai bertentangan dengan peraturan Grup.Di grup ini juga dikenal adanya "Friday Freeday" dan "Weekend no filter" dimana seluruh anggota boleh mem-posting apapun tanpa harus mendapatkan ACC (Accepted) dari admin grup yang berhak menyaring unggahan. Masyarakat yang tergabung dalam grup ini dibebaskan untuk mengunggah apapun asal tidak bertentangan dengan peraturan grup, namun jika kebebasan ini tidak dimanfaatkan sebaik mungkin oleh anggota grup akibatnya terdapat beberapa unggahan yang tidak pantas untuk dibaca. Sehingga membuat 
grup MIK Semar tidak terkendali dan tidak bisa dinikmati.

Oleh karenanya "Friday Freeday" dan "Weekend no filter" yang terakhir diberikan pada 20-22 Oktober lalu melahirkan peraturan baru bagi anggotanya yang ingin mengunggah informasi (Postingan), yaitu setiap Unggahan wajib memakai hashtags atau tanda pagar (\#). Tanda pagar ini akan menjadi syarat wajib yang harus disertakan dalam setiap unggahan agar di ACC atau disetujui oleh admin grup.

Pada dasarnya penggunaan hashtags atau tanda pagar (\#) diperkenalkan pertama kali oleh media sosial twitter untuk mengklasifikasikan pesan (tweets) dengan topik tertentu, yang juga memudahkan pengguna lain untuk mencari dan membagikan topik yang sama. Hashtag biasanya terdiri dari serangkaian karakter (mungkin termasuk angka numerik) yang didahului oleh simbol pound (\#) yang juga disebut hash). Kombinasi ini berfungsi sebagai label untuk pesan itu sendiri dan "linked to a search for those characters" (Sagolla 2009:167). Seiring berjalannya waktu, penggunaan hashtags juga telah merambah ke media social lainnya, diantaranya adalah Instagram, Google+ dan Facebook sejak tahun 2013. Bahkan hashtag tidak lagi terbatas pada dunia online melainkan juga telah muncul dalam lanskap linguistik dan dalam berbagai konteks offline, seperti slogan politik dan pidato, gerakan sosial, dunia periklanan, dan program televise.

Grup MIK Semar telah menjadi rumah kedua bagi warga Semarang untuk berkumpul dan berbagi informasi, sehingga perlu dirawat keberadaannya.Salah satunya dengan penggunaan hashtag pada setiap unggahannya.Karena pada dasarnya, Facebook adalah aplikasi yang sangat mudah digunakan dengan bebas registrasi dimana tersedia dalam berbagai 
bahasa dan mencakup berbagai fitur untuk berkomunikasi.

Permasalahan dalam penelitian ini adalah bagaimana hashtag atau tanda pagar (\#) mampu dimanfaatkan sebagai identitas pesan dalam jaringan komunikasi pada Grup Facebook MIK Semar.Konteks penelitian ini berfokus pada media social Facebook dimana didalamnya terdapat komunitas atau public group yang menggunakan hashtag untuk mendukung komunikasi diantara anggotanya. Hashtag juga bisa menjadi sebuah gerakan atau pengetahuan yang dikembangkan untuk menyebarkan gagasan, berita, atau opini tentang topik tertentu. Hal ini menarik untuk diteliti karena penggunaan internet dan khususnya facebook terus meningkat di Indonesia, tentu ini akan membuat Grup Facebook baru akan terus tercipta dengan berbagai tujuan dan kegunaan.

Dalam penelitian ini yang menjadi kajian merupakan salah satu bentuk penggunaan situs jejaring sosial Facebook. Oleh karena itu, penelitian yang dilakukan ini merupakan bentuk dari Computer Mediated Communication, dimana transaksi komunikasi yang terjadi melalui penggunaan dua atau lebih computer yang berjaringan. Istilah tersebut menggambarkan komunikasi yang terjadi dimediasi oleh format computer, misalnya: pesan instan, chat room, e-mail.Format tersebut diterapkan pada bentuk-bentuk lain dari interaksi berbasis teks seperti pesan teks.

\section{Metodologi Penelitian}

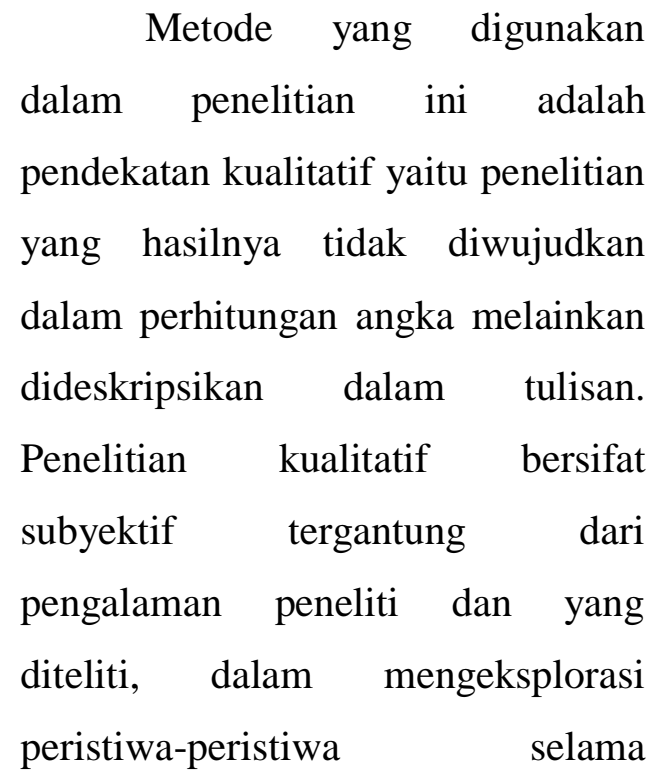


berlangsungnya penelitian, atau memotongnya jika tidak sesuai dengan masalah yang diteliti (Greenhalgh \& Taylor, 1997:2).

Peneliti akan lebih banyak mengarahkan analisis terhadap data kualitatif karena menyangkut aktivitas dan dinamika yang terjadi dalam suatu lingkup kebudayaan virtual. Penelitian ini menitikberatkan pada penelusuran dokumen maupun data online yang terkait dengan penggunaan tanda pagar pada Grup Facebook MIK Semar. Media social dalam konteks ini berkaitan dengan seluruh jaringan untuk berkomunikasi yang memanfaatkan internet, dipilih secara purposive dan tidak terbatas pada lokasi penggunaannya, sebab diutamakan adalah unggahan yang menggunakan hashtags atau tanda pagar (\#) di Grup Facebook MIK Semar.Yakni mencermati berbagai pustaka, dokumen cetak maupun online yang jumlahnya sangat banyak dan dipilih secara sengaja yang ada kaitannya denga topik penelitian.

Teknik ini mencakup seleksi atas dasar kriteria-kriteria tertentu yang dibuat peneliti berdasarkan tujuan penelitian. Biasanya teknik purposive sampling dipilih untuk penelitian yang lebih mengutamakan kedalaman data daripada untuk tujuan representatif yang dapat digeneralisasikan (Kriyantono, 2007:154-155).Teknik analisis data yang dipakai dalam penelitian ini menggunakan tiga alur kegiatan yaitu reduksi data, penyajian data, dan penarikan kesimpulan (Miles \& Huberman, 2009:19). Inti dari analisis data kualitatif terletak pada proses mengkaitkan pernyataan yang menggambarkan fenomena, mengklasifikasikannya, dan melihat konsep-konsep terkoneksi secara komprehensif sebagai hasil penelitian ilmiah (Dey, 1993:31).

Data-data tersebut diproses dalam sejumlah kategori yang mengarah pada upaya generalisasi 
untuk kemudian disajikan secara interpretative dan descriptive.Data yang terkumpul dikompilasi secara tematik berdasarkan informasi yang diperoleh.Kompilasi data dilakukan melalui pemilahan yang relevan dengan masalah penelitian.

\section{Hasil dan Pembahasan}

Gagasan tentang "komunitas" telah lama memiliki posisi penting dalam teori sosial, khususnya sebagai alat untuk menilai dampak perubahan sosial dan sebagai penetral gagasan mengenai massa. Pada pemikiran lebih awal, komunitas merujuk pada sekelompok orang yang berbagi tempat (atau ruang yang terbatas), sebuah identitas serta norma-norma, nilainilai, praktik budaya tertentu, dan biasanya cukup kecil untuk saling mengenal dan berinteraksi. Komunitas jenis ini biasanya menunjukkan beberapa sifat pembedaan berdasarkan status dan para anggotanya, dan dengan hal tersebut menunjukkan hierarki dan bentuk organisasi informal. Serangkaian harapan baru tentang komunitas berkembang seputar komunikasi yang termediasikan computer (computer mediated communication-CMC).

Computer Mediated Communication (CMC) dan Berkembangnya Komunitas Virtual

Computer Mediated Communication (CMC) didefinisikan sebagai suatu proses komunikasi yang dilakukan melalui komputer, yang melibatkan manusia yang terjadi pada konteks tertentu, dimana didalamnya melibatkan proses pembentukan media untuk berbagai tujuan. Hal ini sesuai dengan definisi computermediated communication yakni: "Computer Mediated Communication is a process of human communication via computer, involving people, situated in particular context, engaged in process to shaped media for variety 
of purpose." (Thurlow et al, 2007: 15)

Pada intinya, CMC adalah suatu proses komunikasi atau pertukaran informasi yang dilakukan melalui medium computer.

Kehadiran dunia virtual, membuka kesempatan setiap pihak yang terlibat untuk mengeksistensikan dirinya dengan lebih luas. Apalagi bagi mereka yang aktif di social media. Melalui status, komentar, notes, dan berbagai fasilitas dalam media sosial tersebut banyak orang menunjukkan keberadaannya dengan terus mengupdate segala perkembangan yang ada. (Watie, 2011)

\section{Computer}

Mediated

Communication atau CMC mampu menghadirkan komunitas. Istilah komunitas virtual digunakan untuk menggambarkan level komitmen ddan keterbukaan yang dialami para pengguna. Rheingold menekankan pengguna $\mathrm{CMC}$ untuk membentuk hubungan yang terus menerus.CMC adalah agregasi sosial ketika banyak orang membawa diskusi public cukup panjang, dengan perasaan manusia untuk membentuk hubungan personal dalam cyberspace (Hine, 2000:16-17). Komunitas virtual sebagai komunitas yang didirikan secara sengaja oleh orangorang yang memiliki kepentingankepentingan yang sama yang sering kali berkisar seputar teks atau ungkapan tertentu yang diambil dari tempat-tempat non-CMC (Lindolf \& Schatzer dalam McQuail, 2011:163164).

Grup Facebook MIK Semar juga merupakan bagian komunitas virtual dimana orang-orang yang ada didalamnya memiliki kepentingan yang sama untuk saling berbagi informasi terkait dengan peristiwa, kegiatan, lomba, hiburan, sejarah, event, dll di Kota Semarang untuk dipublikasi umum. Komunitas online seperti ini memiliki keuntungan tambahan pada prinsipnya, terbuka dan mudah diakses dibandingkan 
dengan komunitas di dunia nyata yang seringkali sulit dimasuki (Slevin,2000).

Walaupun komunikasi yang dimediasikan komputer menawarkan kesempatan baru untuk melintasi batasan social dan budaya, hal itu juga secara tidak langsung menguatkan batas-batas yang sama. Mereka ingin menjadi bagian dari komunitas dalam cyberspace harus menyesuakian diri dengan normanorma dan aturannya agar dapat diakui dan diterima (Postman dalam McQuail, 2011:165). Begitu juga dengan Grup Facebook MIK Semar yang memberikan aturan-aturan untuk dipatuhi seluruh anggotanya, berikut adalah aturan-aturan bagi seluruh anggota Grup Facebook MIK Semar

(https://web.facebook.com/groups/M IKSEMAR) :

1. Isi postingan tidak mengandung SARA, PORNOGRAFI dan atau yang bertentangan dengan hukum di Indonesia.

2. Informasi yang diberikan lengkap, jelas, akurat (Siapa, Oleh Siapa, Kapan, Dimana, Dengan Apa, Bagaimana)

3. Tindakan hukum yang terkait dengan pihak/orang lain, DIWAJIBKAN melampirkan Surat Laporan Kepolisian

4. Bukan berisi Curahan hati pribadi maupun foto selfie diri sendiri

5. Promo Jual atau Beli barang/Jasa diperbolehkan setiap hari Sabtu mulai pukul 00.00 sampai dengan Minggu Pukul 23.59 WIB (dengan catatan BUKAN barang/jasa yg dilarang atau terbatas peredarannya)

6. Posting korban kecelakaan WAJIB DIBLURKAN utk menghormati korban dan keluarga.

7. Apabila isi berita merupakan hasil sharing dari tempat lain, diwajibkan untuk 
mencantumkan sumber beritanya

8. Memberikan postingan yang bermanfaat bagi seluruh member grup MIK SEMAR

9. Setiap anggota diharapkan dapat mendukung penuh kebijakan pemerintah demi kenyamanan, keamanan dan keselamatan bersama (seperti TIDAK share Lokasi Operasi Ketertiban).

10. Diharapkan sebelum memberikan informasi, memeriksa terlebih dahulu apakah telah ada atau belum (TIDAK doubel post)

11. Ikut menjaga grup demi kenyamanan bersama, isi postingan yang melanggar dapat dilaporkan (report) ke admin untuk dihapus.

12. Setiap Isi dari kiriman menjadi tanggung jawab mutlak si pengirim. (Ref: UU ITE)

\section{Hashtags atau Tanda Pagar (\#) Sebagai Identitasi Pesan}

$\begin{array}{crr}\text { Media } & \text { sosial telah } \\ \text { melahirkan bentuk baru dalam }\end{array}$ berkomunikasi dan berinteraksi dengan publik.Salah satu alat yang paling inovatif adalah hashtag. Sejak karyawan Twitter bernama Chris Messina mengirim tweet pertama yang berisi sebuah hashtag pada tahun 2007 (Kirkpatrick, 2011), hashtags telah menjadi populer dan menyebar ke platform media sosial lainnya. Hashtag menunjukkan topik atau tema, dan merupakan inovasi penting dalam komunikasi di media sosial. Penggunaan hashtag sangat kuat karena memang begitu partisipatif. Hashtag tidak diputuskan oleh seperangkat pengguna yang telah ditentukan sebelumnya. Sistem hashtag merupakan pemberian tag, pengorganisasian, dan sistem klasifikasi. Hashtags mengklasifikasikan pesan, meningkatkan pencarian, dan 
memungkinkan organisasi untuk menghubungkan pesan dengan topik yang sedang berkembang dan komunitas yang tergabung dalam hashtag tersebut. Singkatnya, hashtag bisa memimpin pembentukan "ad hoc public" atau jaringan public yang berkembang disekitar hashtag (Bruns \& Burgess, 2011). Jaringan/komunitas ini bisa singkat dan timbul sebagai tanggapan saat keadaan darurat ataupun krisis. Hashtag juga bisa menjadi sebuah gerakan atau pengetahuan yang dikembangkan untuk menyebarkan gagasan, berita, atau opini tentang topik tertentu.

Tanda pagar telah memberi warna yang berbeda dalam social media, dimana media social telah dibekali dengan User generated Content (UGC) dimana dapat menciptakan keterlibatan warganet di media sosial. Pertama, hashtags telah mengubah bagaimana kita berbicara (verbal maupun nonverbal), misalkan penggunaan hashtags \#YesWeCan \#Smile \#GoodMorning yang biasanya katakata atau ekspresi tersebut digunakan dalam sehari-hari. Kedua, hashtags telah merubah bagaimana cara memasarkan sebuah produk atau kampanye, misalkan penggunaan hashtags \#Paytreninaja, \#Peluangbisnis, \#Sepatumurah, \#MakeAmericaGreatAgain, \#Salam2jari. Ketiga, hashtags telah menjadi sarana untuk menemukan sumber konten yang ada di media social, misalkan kita mau mencari informasi tentang lowongan kerja, kita hanya butuh mengetik \#lowongankerja di bagian "search" yang tersedia di media social maka semua informasi terkait lowongan kerja akan muncul. Keempat, hashtags telah menjadi cara baru dalam melakukan gerakan sosial, misal penggunaan hashtags \#SaveKPK, \#ShameOnYouSBY, \#GerakanAntiNarkoba dan lain-lain yang sempat menjadi viral di media sosial. Kelima, hashtags telah mengubah bagaimana kita 
membangun sebuah komunitas virtual, karena dengan penyertaan hashtags yang diikuti dengan pesan atau konten berkualitas maka akan mudah untuk mengembangkan hubungan dalam komunitas virtual, misalkan saja penggunaan hashtags dalam komunitas virtual Grup facebook MIK SEMAR sebagai identitas pesan untuk membangun hubungan yang lebih baik.

Sejak 2013, fitur hashtags (\#) telah digunakan di Facebook. Dalam grup Facebook MIK Semar, hashtags (\#) bukan lagi digunakan untuk mengelompokkan atau menghubungkan topik yang serupa, melainkan digunakan sebagai identitas pesan dari setiap unggahan yang diunggah ke dalam grup, penggunaan hashtags diwajibkan oleh pengelola grup seperti yang disampaikan oleh Dalang Utama MIK Semar dalam postingannya $\begin{array}{lll}\text { pada } & 23 & \text { Oktober } \\ & 2017\end{array}$ (https://web.facebook.com/groups/M
IKSEMAR/permalink/157134430964

9193/).

Diantaranya adalah Pertama, \#MIKSEMARTANYA untuk mengidentifikasikan pesan yang diunggah dimaksudkan untuk bertanya tentang suatu hal ke dalam Grup.

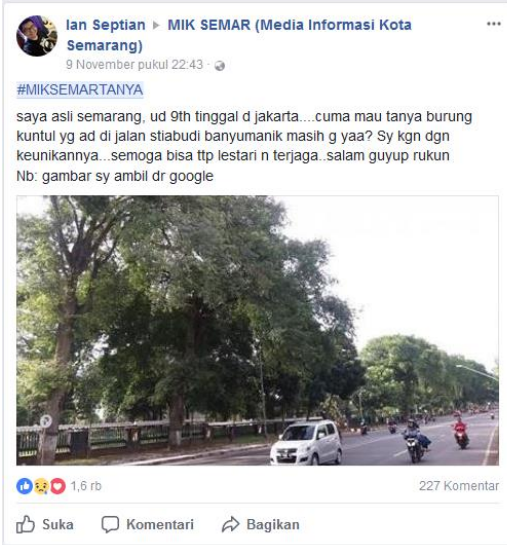

Gambar 1. Contoh Penggunaan hashtags \#MIKSEMARTANYA

Kedua, \#MIKSEMARINFO untuk mengidentikasi pesan yang diunggah dimaksudkan untuk memberikan informasi ke grup tentang peristiwa 
maupun segala sesuatu hal.

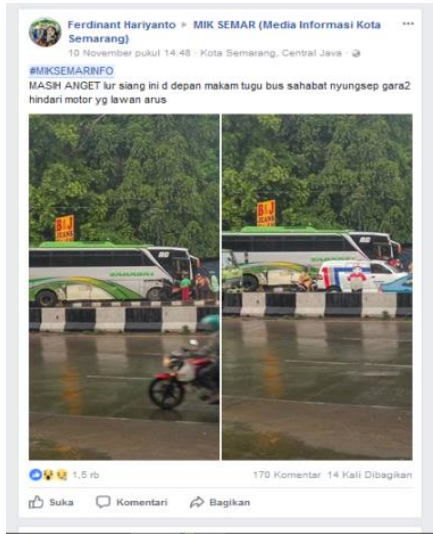

Gambar 2. Contoh Penggunaan hashtags \#MIKSEMARINFO

Ketiga, \#MIKSEMARLOKER untuk mengidentifikasi pesan yang diunggah sebagai informasi tentang lowongan pekerjaan.

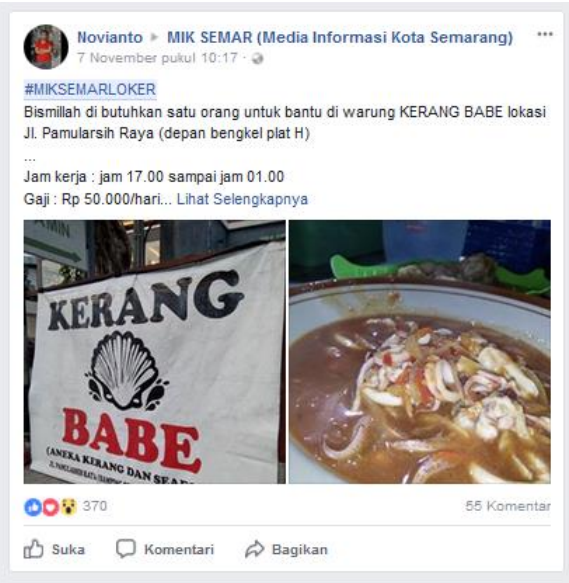

Gambar 3. Contoh Penggunaan hashtags \#MIKSEMARLOKER
Keempat, \#MIKSEMARPROMOSI untuk mengidentifikasi pesan yang diunggah sebagai informasi tentang produk yang dipromosikan. Produk yang dipromosikan bisa bersifat pribadi maupun mempromosikan milik orang lain. Dengan \#MIKSEMARPROMOSI anggota atau warga Grup Facebook MIK SEMAR dapat melakukan upaya pemasaran secara gratis.
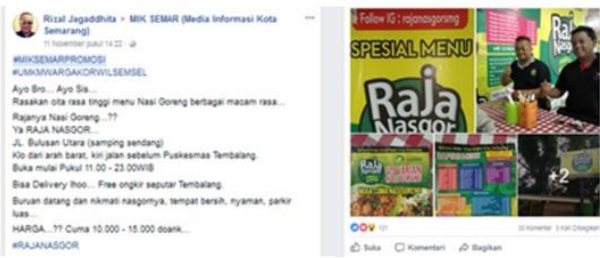

Gambar 4. Contoh Penggunaan hashtags \#MIKSEMARPROMOSI

Kelima, \#MIKSEMARSAPA untuk mengidentifikasi pesan yang diunggah dimaksudkan sebagai informasi yang memuat segala bentuk aktifitas anggota atau warga Grup Facebook MIK SEMAR dalam perannya membangun wilayah Kota Semarang, isi Postingan dapat berupa Gambar atau Video dengan mencantumkan secara lengkap apa 
dan bagaimana kegiatan warga tersebut. Selain itu, \#MIKSEMARSAPA juga dapat di manfaatkan untuk menyapa temanteman Kecil atau teman Sekolah yang lama tidak berjumpa, sehingga di harapkan melalui Grup Facebook MIK SEMAR ini Silahturahim dapat terajut kembali.

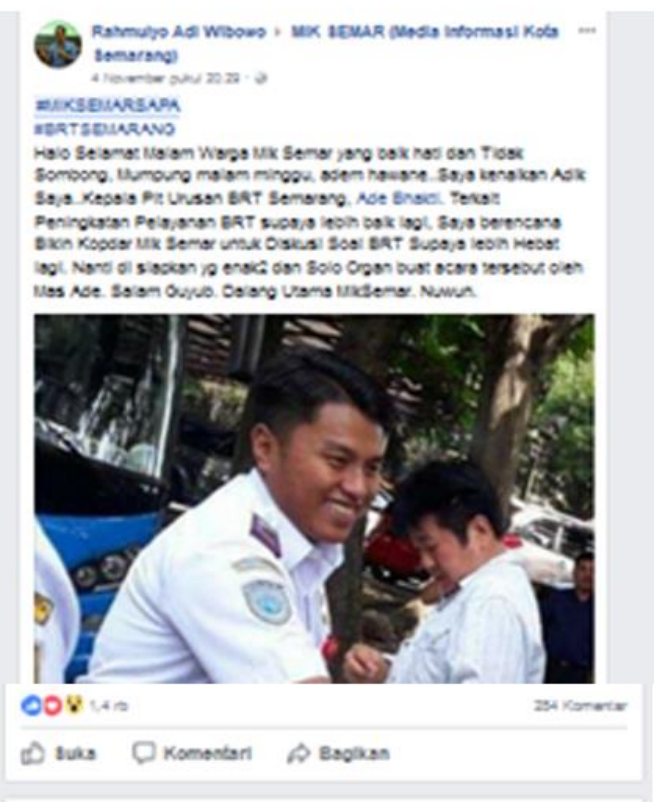

Gambar 5. Contoh Penggunaan hashtags \#MIKSEMARSAPA

$$
\begin{aligned}
& \text { Keenam, \#MIKSEMARTAWA } \\
& \text { untuk pesan yang diunggah } \\
& \text { dimaksudkan sebagai kisah atau }
\end{aligned}
$$

gambar lucu yang bertujuan untuk menghibur anggota atau warga Grup Facebook MIK SEMAR. \#MIKSEMARTAWA ini boleh berisi tulisan-tulisan Lucu, boleh perang gambar asal tidak negatif, atau video lucu.

Bercanda ala Mik Semar dilarang atau tidak boleh memuat hal yang bersifat pornografi, memuat unsur SARA, Meme tokoh publik, atau candaan yang menyinggung perasaan orang atau Kelompok orang. Pelanggaran terhadap hal tersebut di atas serta isi postingan yang lain akan di jatuhi Sangsi Banned atau Block Permanen.

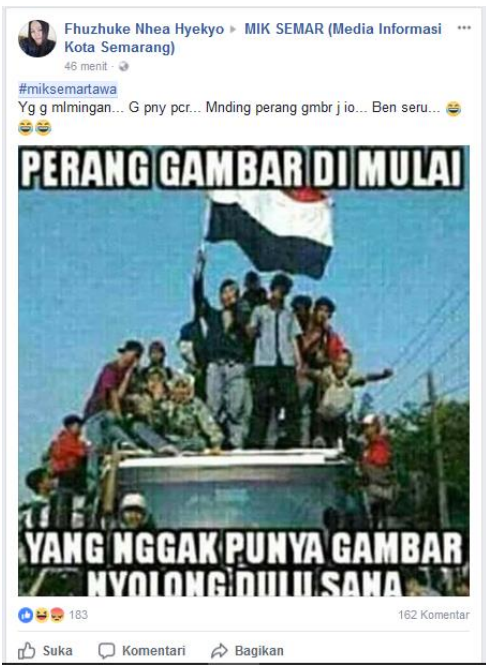


Gambar 6. Contoh Penggunaan hashtags \#MIKSEMARTAWA

Itulah beberapa jenis hashtag atau tanda pagar (\#) yang sering digunakan dalam Grup Facebook MIK SEMAR, karena tanpa hashtags unggahan tidak akan bisa tampil dalam laman Grup. Admin Grup Facebook MIK SEMAR tidak akan memberikan persetujuan pada setiap postingan tanpa menggunakan hashtags. Khusus unggahan dengan \#MIKSEMARSAPA dan \#MIKSEMARSAPA hanya akan ditayangkan pada hari sabtu dan minggu oleh pengelola.

Tanda pagar (\#) tersebut harus diletakkan sebelum materi unggahan atau sebelum informasi inti apa yang ingin disampaikan. Dengan tanda pagar dalam facebook, maka teks tersebut akan memiliki struktur yang berbeda dengan teks yang lain, teks dengan tanda pagar akan menjadi lebih tebal atau bold. Penggunaan tanda pagar ini menjadi pembeda antara komunitas virtual
Grup facebook MIK SEMAR dengan komunitas virtual yang lain.

Media sosial mengajak siapa saja untuk berpartisipasi dengan memberi feedback secara terbuka, memberi komentar, serta berbagi informasi dalam waktu yang cepat dan tak terbatas.Media sosial menghapus batasan-batasan dalam bersosialisasi, seperti ruang dan waktu.Akibatnya, setiap individu dapat berkomunikasi kapanpun dan dimanapun mereka berada (Safko dalam Hutagalung, 2014:368).

Disaat penggunaan hashtags menjadi tren, apa yang membedakan pengguna internet biasa dan yang tergabung dalam komunitas virtual? dalam riset yang dilakukan oleh TINT (Social Media Aggregator) terdapat 4 kriteria komunitas. Pertama, Self-Identification, anggota harus mengenal batas-batas keanggotaannya dan mereka terlibat dalam aturan didalamnya. Dalam MIK Semar terbagi menjadi beberapa tipe anggota diantaranya 


\begin{tabular}{lrll} 
Dalang Utama $\quad$ (Pengelola), & & \multicolumn{2}{l}{ mendasari orang untuk bergabung } \\
Punggawa (Admin), Provost & dalam komunitas virtual adalah \\
(Anggota yang berhak menyaring & untuk memenuhi kebutuhan akan \\
informasi yang ada dalam Grup), dan & informasi dan menyampaikan \\
Warga MIK Semar (anggota biasa & aspirasi.
\end{tabular}
yang hanya bisa sebatas mengamati, menanggapi dan mengunggah informasi).

Kedua, Influence, anggota memiliki tingkat pengaruh yang berbeda-beda, Seperti dijelaskan sebelumnya bahwa setiap jenis anggota memiliki pengaruh yang berbeda, dalam MIK Semar pengaruh yang besar dimiliki oleh Dalang Utama dan Punggawa sebagai pengelola (admin).

Ketiga, Shared Emotional Connection. Anggota merasa istimewa karena telah bergabung dalam komunitas virtual, maka dari itu ada perasaan untuk menjaga agar komunitas virtualnya berjalan baik.Dalam MIK Semar agar Grup tertata, maka digunakan hashtags sebagai identitas pesan yang harus ditaati seluruh anggota. Keempat, Fulfillment of needs, salah satu yang

\section{Kesimpulan}

Berdasarkan analisis yang telah dilakukan penulis, Computer Mediated Communication atau CMC mampu menghadirkan komunitas. Grup Facebook MIK Semar juga merupakan bagian komunitas virtual dimana orang-orang yang ada didalamnya memiliki kepentingan yang sama untuk saling berbagi informasi terkait dengan peristiwa, kegiatan, lomba, hiburan, sejarah, event, dll di Kota Semarang untuk dipublikasi umum. Penggunaan Hashtags menunjukkan topik atau tema, dan merupakan inovasi penting dalam komunikasi di media social.

Tanda pagar telah memberi warna yang berbeda dalam social media, dimana media social telah dibekali dengan User generated Content (UGC) yang dapat 
menciptakan keterlibatan warganet di media sosial. Hashtags telah merubah bagaimana kita berbicara (verbal maupun non-verbal), hashtags telah merubah bagaimana cara memasarkan sebuah produk atau kampanye, hashtags telah menjadi sarana untuk menemukan sumber konten yang ada di media social, hashtags telah menjadi cara baru dalam melakukan gerakan sosial, hashtags telah merubah bagaimana kita membangun sebuah komunitas virtual Sebagaimana penggunaan hashtags dalam komunitas virtual Grup Facebook MIK SEMAR sebagai identitas pesan untuk membangun hubungan yang lebih baik dan mendukung komunikasi diantara anggotanya.

\section{Dalam Grup Facebook MIK}

Semar, hashtags bukan lagi digunakan untuk mengelompokkan atau menghubungkan topik yang serupa, melainkan digunakan sebagai identitas pesan dari setiap unggahan yang di-posting ke dalam grup, penggunaan hashtags diwajibkan oleh pengelola grup untuk memperjelas maksud dari pesan yang diunggah, seperti hashtags \#MIKSEMARTANYA, \#MIKSEMARINFO, \#MIKSEMARPROMOSI, \#MIKSEMARTAWA, \#MIKSEMARSAPA yang diletakkan pada awal unggahan. Setiap anggota komunitas harus mengenal batas - batas keanggotaannya dan mereka terlibat dalam aturan didalamnya.

\section{Daftar pustaka}

Bruns, A., \& Burgess, J. E. (2011, August).The use of Twitter hashtags in the formation of ad hoc publics. Paper presented at the 6th European Consortium for Political Research General Conference.University of Iceland:Reykjavik.

Dey, Ian. (1993). Qualitative Data Analysis A User-Friendly Guide For Social Scientists. London and New York : Routledge-Taylor and Francis Group 
Hine, Christine. (2000). Virtual Ethnography. London: Sage

Hutagalung, Inge .(2014). "Etika dan Media Sosial" dalam Masa Depan Komunikasi, Masa Depan Indonesia: Demokrasi Dalam Ruang Virtual.Jakarta:ISKI

Miles, Matthew B and A. Michael Huberman .(2009). Qualitative Data Analysis, atau Analisis Data Kualitatif, terjemahan Tjetjep Rohendi.Jakarta : Univ. Indonesia Press.

McQuail, Denis. (2011). Teori Komunikasi Massa McQuail, Edisi 6 Buku 1. Jakarta: Salemba Humanika

Kaplan, Andreas M and Michael Haenlein. (2010). "Users of the world, unite! The challenges and opportunities of Social Media". Business Horizons

Nasrullah, R. (2014). Teori dan Riset MediaSiber.Jakarta : Kencana.

Thurlow et al.(2004). Computer

Mediated Communication:

Social Interaction and the

Internet.London : Sage Publication

\section{Artikel dalam Jurnal Ilmiah}

Ubayasiri, K. (2006). Internet and the public sphere: A glimpse of YouTube. Central Queensland
University, 2. JOUR.

Watie, E. D. S. (2011). Komunikasi dan Media Sosial (Communications and Social Media). Jurnal The Messenger, (Vol 3, No 2 (2011): The Messenger), 69-74. JOUR. Retrieved from http://journals.usm.ac.id/index.p $\mathrm{hp} /$ themessenger/article/view/270

Watie, E. D. S. (2012). Media Sosial yang Dibenci yang Ditakuti. Jurnal The Messenger, (Vol 4, No 2 (2012): The Messenger), 14-18. JOUR. Retrieved from http://journals.usm.ac.id/index.p $\mathrm{hp} /$ the-

messenger/article/view/155

\section{Internet}

APJII: Infografis Panetrasi dan Perilaku Pengguna Internet di Indonesia.(2016). Tersedia dari:

https://www.apjii.or.id/conte nt/read/39/264/SurveiInternet-APJII-2016 diakses 30 Oktober 2017

Facebook.(2017). Peraturan Grup MIK Semar. Tersedia dari: https://web.facebook.com/gro ups/MIKSEMAR diakses 2 November 2017) 
Facebook.(2017).Peraturan Memakai Hashtags.

https://web.facebook.com/gro ups/MIKSEMAR/permalink/ 1571344309649193/ diakses

2 November 2017)

TINT. How Hashtags Changed The World.(2017). Tersedia dari: http://www.tintup.com/media how-hashtags-changed-the world.pdfdiakses 10

November 2017

Kirkpatrick, M. (2011).The first hashtag ever tweeted on Twitter: They sure have come a long way. Tersedia dari ReadWriteWeb.com diakses 7 November 2017. 